\title{
What type of labor lies behind the on-demand economy? New research based on workers' data
}

\author{
Santiago Melián-González ${ }^{*}$ and Jacques Bulchand-Gidumal \\ TIDES Institute of Tourism and Sustainable Development, University of Las Palmas de Gran Canaria, Facultad de \\ Economía, Empresa y Turismo, Campus Universitario de Tafira, Las Palmas, Spain \\ ${ }^{\star}$ Corresponding author. Email: santiago.melian@ulpgc.es
}

(Received 11 September 2017; revised 31 July 2018; accepted 4 August 2018)

\begin{abstract}
On-demand and gig economy are names commonly used when discussing issues related to labor in the collaborative economy. Some of the specific digital platforms in this economy, including Uber and TaskRabbit, and Upwork are quite popular. The term digital labor market has been suggested to distinguish the work mediated by these platforms from that of the traditional labor market. The theoretical work conditions and characteristics of this digital labor market are similar to those of negative nonstandard work arrangements. However, more empirical evidence is required because most of the findings about work conditions are based on anecdotal evidence and the analysis of the platforms' rules. This study collects the characteristics commonly attributed to the digital labor market and analyzes them based on data about 465 workers extracted from two important digital labor platforms. Our results confirm and refine some of the beliefs found in the literature.
\end{abstract}

Keywords: on-demand economy; gig economy; sharing economy; collaborative economy; nonstandard employment

\section{Introduction}

Significant technological innovations have influenced the world of work, creating new occupations, services, and tasks (Goldin \& Katz, 2009). There is no doubt about the extent to which the internet has revolutionized society and the economy. One of its consequences is what has been called the collaborative/sharing economy (Sundararajan, 2016), with companies emerging such as Airbnb and Uber, which are well known due to their many users and frequent presence in the media. In addition to these firms, others have arisen following the same philosophy, that is, the creation of virtual platforms that act as intermediaries between individuals who provide and demand products and services. Because these exchanges are strongly based on the providers' performance, and consumers pay for the services they receive, it has been proposed that a new form of work is emerging.

The previously mentioned exchanges involve temporary and on-demand work, and so gig economy and on-demand economy are common names used for this type of activity (Davis, 2015; Slaughter, 2015; Huws, Spencer, \& Syrdal, 2018). Furthermore, because individuals can offer a large variety of tasks and services in this digital context, the term digital labor market (henceinafter DLM) was recently proposed to represent this new form of work (Codagnone, Abadie, \& Biagi, 2016). The latter has also been understood as an additional nonstandard work arrangement option that fits current employers' hiring tendencies (Katz \& Krueger, 2016). In general, nonstandard work arrangements are usually associated with negative work conditions (Doeringer \& Piore, 1971). 
DLM is expected to spread significantly (Gheorghe, 2015; Huws, Spencer, \& Syrdal, 2018). Some ad-hoc statistics are appearing that confirm these expectations. For example, Lehdonvirta (2017) estimates an increase of 26\% from July 2016 to July 2017.

Most of the extant opinions about the DLM draw on particular experiences that individuals publish on the internet (e.g., Shontell, 2011) and the analysis of the way DLM platforms are run (e.g., Sprague, 2015). These opinions are mostly unfavorable. At the same time, some authors mention positive consequences of the spread of this type of labor, but they admit that the negative aspects seem to predominate (Kalleberg \& Dunn, 2016).

Current studies based on platform workers' data seem to support the unfavorable statements about the DLM. Nevertheless, few studies have been carried out, and because the DLM is heterogeneous, this lack of research is more pronounced. Therefore, there has been a call to provide more empirical evidence that refines the common rhetoric characterizing the DLM (Codagnone, Abadie, \& Biagi, 2016; Schor \& Attwood-Charles, 2017). Thus, the objective of this study is to analyze the DLM attributions present in the literature by drawing on platform workers' data.

In this study, data from two important and different types of digital labor platforms (TaskRabbit and Trip4real) were downloaded. The article unfolds as follows. The first section contextualizes the on-demand economy in the collaborative economy field. The second section describes the nonstandard work arrangement concept and its characteristics. The third section describes the framework of the DLM. Next, the objective of the research is described, and the methodology is explained. Then, the results are described, and the conclusions and limitations are presented.

\section{Collaborative economy and on-demand economy}

The collaborative economy has emerged with the spread of the internet. Thus, it relies on all the benefits that the internet provides to consumers, on the one hand, such as the quantity and quality of customized information with minimal effort and cost (Jepsen, 2007), and to providers, on the other, such as the opportunity to gain a larger audience and interact with it at low operating costs (Kiang, Raghu, \& Shang, 2000). The collaborative economy is a broad term that involves different types of individual relationships through the internet. Many of these relationships consist of digital platforms where labor is exchanged for economic compensation (Leighton, 2016). Because these exchanges seem to be very short term and depend on direct consumer orders, the terms gig economy and on-demand economy have been proposed (Davis, 2015; Slaughter, 2015; Huws, Spencer, \& Syrdal, 2018). The on-demand economy directly relies on individuals' work, and its importance is recognized in the following reports released by relevant institutions: European Commission (2016), International Labor Organization (Berg, 2016), Organisation for Economic Co-Operation and Development (2016), and the United States Department for Labor (2016), among others.

\section{Nonstandard work arrangements}

The labor market includes both standard and nonstandard employment. A permanent and fulltime job is usually considered standard employment, and jobs that deviate from these characteristics are considered nonstandard work arrangements (Horemans, 2016). Dual market theorists state that there are two main types of jobs: primary jobs with high wages, good working conditions, and promotion opportunities; and secondary jobs, characterized by low wages, bad working conditions, unstable employment, and few promotion opportunities (Doeringer \& Piore, 1971).

Secondary jobs are usually linked to nonstandard work arrangements (Hudson, 2007). Atkinson (1984) and Kalleberg (2003) explain that companies implement two types of flexibility 
measures, functional and numerical, which produce two types of workforces, respectively: core employees with a permanent, full time job; and peripheral employees, who are employed under an array of nonstandard work arrangements such as temporary contracts, temporary work agencies, independent contractors, and the outsourcing of activities.

Nonstandard work arrangements have significantly increased lately (Horemans, 2016; Spreitzer, Cameron, \& Garrett, 2017), and recent figures show that a new type of nonstandard work arrangement, the digital on-demand economy, has joined the existing ones (Katz \& Krueger, 2016; Huws, Spencer, \& Syrdal, 2018). This on-demand economy is based on the existence of digital platforms such as Uber, TaskRabbit, and Upwork. The global scope of many of these platforms, the venture capital funding that most of them have available, and the spread of nonstandard employment allow us and other authors (e.g., Huws, Spencer, \& Syrdal, 2018) to believe that this type of work will expand even more in the next few years.

\section{The DLM}

In order to distinguish the particular type of work that the digital on-demand economy is triggering, Scholz (2013) has suggested the term 'digital labor market.' Graham, Hjorth, and Lehdonvirta (2017) and Kalleberg and Dunn (2016) have argued that this labor market is not completely new, but rather represents the digital version of nonstandard work arrangements. Additionally, these authors consider that the DLM operates under a new relationship model that has important implications for the nature of work and the quality of jobs. This changing relationship, in addition to the growth expectations in the DLM, require further research.

Because it is a very recent field, DLM theory is beginning to be developed. Codagnone, Abadie, and Biagi (2016) and Kalleberg and Dunn (2016) highlight the insufficient amount of empirical evidence supporting many of the current assumptions about the DLM, and they call for more research.

De Groen, Maselli, and Fabo (2016) and Kalleberg and Dunn (2016) state that DLM is not homogenous. In this regard, Codagnone, Abadie, and Biagi (2016) consider that it can be divided into two broad categories: online labor markets and mobile labor markets. The former include work that can be electronically transmitted, whereas the latter involve physical work delivered in a localized manner. Considering, in addition, the level of skills the work demands, Codagnone, Abadie, and Biagi (2016) propose four relatively independent DLMs: online labor markets and mobile labor markets that require low-to-medium levels of skills (e.g., Amazon Mechanical Turk and TaskRabbit, respectively); and online labor markets and mobile labor markets that require medium-to-high levels of skills (e.g., Upwork and Takelessons, respectively).

Working in the DLM can involve positive and negative working conditions, although the limited available evidence seems to support the negative aspects more than the positive ones (Aloisi, 2016; Berg, 2016; Codagnone, Abadie, \& Biagi, 2016; Kalleberg \& Dunn, 2016). The latter typically include the flexibility and autonomy workers can enjoy with this type of work (Slaughter, 2015; Kalleberg \& Dunn, 2016). Nevertheless, this issue is debatable, due to the control that many platforms exert over workers (Codagnone, Abadie, \& Biagi, 2016; Huws, 2016). Although there are data about the workers' satisfaction, they are based on studies commissioned by the platforms involved (Elance-Odesk, 2014; Hall \& Krueger, 2015). The DLM unfavorable facet coincides largely with what has been called worker economic vulnerability, which has been found in traditional nonstandard work arrangements such as agency work (Cochrane \& McKeown, 2015). The DLM negative work characteristics and working conditions most often mentioned in the literature revolve around low individual protection and the type of work demanded. Table 1 includes these characteristics from two sources of information: the analysis of the platforms and workers' data available on the platforms.

Analyses focused on digital labor platforms, particularly the study of their operations and rules, have revealed that in the DLM, workers are self-employed, and they must assume the cost 
Table 1. Negative work characteristics in the digital labor market

\begin{tabular}{|c|c|c|}
\hline & Based on platform analysis & Based on workers' data in the platforms \\
\hline Lack of social protection & $\begin{array}{l}\text { De Groen, Maselli, and Fabo } \\
\text { (2016), Sprague (2015) }\end{array}$ & Berg (2016) \\
\hline Short-length assignments & $\begin{array}{l}\text { Aloisi (2016), Huws (2016), Sprague } \\
\quad(2015)\end{array}$ & $\begin{array}{l}\text { De Groen, Maselli, and Fabo (2016), Maselli and Fabo } \\
\text { (2015) }\end{array}$ \\
\hline Low-skilled work & $\begin{array}{l}\text { Drahokoupil and Fabo (2016), } \\
\text { Huws (2016) }\end{array}$ & De Groen, Maselli, and Fabo (2016) \\
\hline Uncertainty & $\begin{array}{l}\text { Davis (2015), De Stefano (2016), } \\
\text { Sprague (2015) }\end{array}$ & Davis (2015), De Stefano (2016), Sprague (2015) \\
\hline High competition & Huws (2015), De Stefano (2016) & Maselli and Fabo (2015) \\
\hline $\begin{array}{l}\text { Low bargaining power } \\
\text { for workers }\end{array}$ & $\begin{array}{l}\text { Aloisi (2016), De Groen, Maselli, } \\
\quad \text { and Fabo (2016) }\end{array}$ & - \\
\hline Long work days & Berg (2016), Todolí-Signes (2017) & - \\
\hline $\begin{array}{l}\text { Subordination to } \\
\text { customer experience }\end{array}$ & $\begin{array}{l}\text { Aloisi (2016), De Groen, Maselli, } \\
\quad \text { and Fabo (2016), Huws (2016) }\end{array}$ & - \\
\hline $\begin{array}{l}\text { Insufficient earnings to } \\
\text { make a living }\end{array}$ & - & $\begin{array}{l}\text { Berg (2016), De Groen, Maselli, and Fabo (2016), Hall } \\
\text { and Krueger (2015), Maselli and Fabo (2015) }\end{array}$ \\
\hline Low work demand & - & $\begin{array}{l}\text { Berg (2016), De Groen, Maselli, and Fabo (2016), } \\
\text { Maselli and Fabo (2015) }\end{array}$ \\
\hline
\end{tabular}

Source: own elaboration.

of social protection in case of sick leave, unemployment, holidays, and retirement, which is difficult because of their low incomes. DLM involves consumers who demand labor to accomplish tasks that usually have a short length and mostly require low-level skills. Apart from the demand for easy tasks, the low qualification level stems from the fact that large work activities are decomposed into small and simple pieces of work. All of this generates low earnings. In addition, there is no guarantee about the number of tasks that will be available. Because consumers' demands are lower than the numbers of workers on platforms, there is strong competition. Workers must accept the platforms' rules if they want to participate, and the traditional conditions that drive workers' bargaining power are not present (e.g., communication among workers, shared spaces). Because there are no rules about maximum working hours, and workers cannot reject any demanded tasks, due to the uncertainty of obtaining more orders or fear of penalization by platforms, individuals may be obligated to work long days. Finally, platforms ask customers to rate the worker's performance. These reviews become visible and are then used to guide consumers' hiring decisions. In addition, platforms can penalize workers for bad reviews.

Few studies (Hall \& Krueger, 2015; Maselli \& Fabo, 2015; Berg, 2016; De Groen, Maselli, \& Fabo, 2016) provide results based on platform workers' data, as Table 1 shows. Hall and Krueger's (2015) research is based on data from Uber, a company that belongs to the mobile labor market and requires low-to-medium levels of skills. The most frequent reason for joining Uber was to get more income ( $91 \%$ of the sample). Moreover, $61 \%$ of the drivers had another job, which means that for these individuals, the Uber income was probably not sufficient to make a living.

De Groen, Maselli, and Fabo (2016) research is based on the ListMinute Belgian platform, where various physical tasks are mainly demanded. The authors found that most of the workers (94.6\%) on the platform had not performed any tasks. On average, earning workers received $€ 200$ over the course of 2 years. Most of these workers got their income by doing one task (57\%), 
and those with a very high number of tasks (i.e., between 20 and 78 tasks) represented only $2 \%$ of the earning workers. This supports what Codagnone, Abadie, and Biagi (2016) suggest as a characteristic of DLM: the superstar effect, that is, a small portion of the workers perform the majority of the work. Most of the tasks performed required a low level of skills.

Maselli and Fabo (2015) studied the case of a platform that intermediates in an online labor market requiring highly skilled work (architectural and interior design) and mainly operating in Italy and Serbia. In all, 52\% of the 1,008 professionals registered on the platform had performed more than one task. On average, each of the previous workers submitted 4.8 projects and were successful 0.7 times (i.e., with a compensation). Total average earnings were $€ 211$, or $€ 47$ per submission. The maximum income a worker had earned was $€ 6,892$. The number of clients' requirements accomplished by workers was 267 . The authors estimated an approximate gross earning per hour of $€ 5$. Considering the average monthly salary in Serbia and Italy, Maselli and Fabo (2015) concluded that Serbian workers could make a living through the platform, but Italian workers could not.

Finally, Berg (2016) analyzed the worker characteristics of two platforms (Amazon Mechanical Turk and Crowdflower) that belong to the online labor market and require low-tomedium-level skills. Overall, the most important reason for doing this work was to complement pay from other jobs (60\% had other paid jobs). In a typical week, workers did $28.4 \mathrm{hr}$ of work (of which, $23 \%$ were dedicated to unpaid administrative tasks), with earnings that ranged from $\$ 1$ to $\$ 5.5 / \mathrm{hr}$. Regarding this aspect, low pay and insufficient work were very frequent worker concerns, and only $10 \%$ paid social security.

\section{Objective of this study}

As mentioned above, Codagnone, Abadie, and Biagi (2016) and Schor and Attwood-Charles (2017) state that the on-demand economy is characterized by a high rhetorical content, and that the DLM framework, particularly the mobile labor market, requires more empirical evidence. A common belief about labor in the DLM is that it involves negative work conditions. Most of the current unfavorable opinions rely on platforms' procedures, and so information based on workers' activity in the platform is needed to complement the few available studies. These studies present several weaknesses. One of them is not completely independent because it was promoted by Uber (Hall \& Krueger, 2015). Another study (De Groen, Maselli, \& Fabo, 2016) is based on a limited-sized platform that focuses its activity in a country where only 10 cities have a population greater than 100,000 individuals. The study by Maselli and Fabo (2015) also used a platform with a very small size, which could have conditioned the results showing that the number of registered tasks was low, and, consequently, the earnings received were also low. In addition, the type of work performed by workers is hardly considered. Finally, Berg's (2016) study focuses on a very specific type of online labor market associated with very low fees. Therefore, the objective of this research is to analyze the negative work characteristics of the DLM shown in Table 1, drawing on platform workers' data.

\section{Methodology}

\section{Platforms}

In January 2016, data from workers who provide services through two digital labor platforms in the mobile labor market (TaskRabbit and Trip4real) were downloaded. TaskRabbit was chosen because it is considered one of the main mobile labor market platforms (Isaac, 2015). Thus, it overcame the limitation of the studies described above, regarding the size of the platform. According to the information ${ }^{1}$ provided on the platform, it offers more than 30,000 workers to

\footnotetext{
${ }^{1}$ https://www.taskrabbit.com/about
} 
perform a large variety of tasks. Following Sundararajan (2014), TaskRabbit is a general-purpose labor platform, where consumers can find providers for multiple labor demands. Although the platform is mainly focused on physical work, such as minor home repairs, moving and packing, and furniture assembly, consumers can also ask for workers to perform cognitive-based tasks such as web design. Codagnone, Abadie, and Biagi (2016) consider that working through TaskRabbit mostly requires low-to-medium-level skills.

Trip4real was a professional service supply platform, particularly of tourism experiences such as those offered by tourist guides (e.g., routes and excursions). It was one of the main platforms offering tourism experiences (Noguera Vivo et al., 2014). The platform was recently acquired by Airbnb, and so the Trip4real website has been integrated into what is called Airbnb Experiences. When the platform was acquired, the number of workers exceeded $3,000^{2}$. Codagnone, Abadie, and Biagi (2016) do not mention Trip4real, but they consider that work involving interactive and face-to-face tasks (e.g., Takelessons) requires medium-to-high-level skills. This is the case of the services provided through Trip4real. In fact, many of them are associated with the tourist guide job, which requires high-level knowledge about history, geography, and art.

\section{Data collection}

Because the activity data of these two platforms are not available, one of the researchers registered as a consumer in each platform and manually downloaded workers' data, which were put into a spreadsheet to create a database that was imported to the statistics analysis package (SPSS). On both platforms, obtaining the workers' data involved reading all the available information shown in each worker profile. Only workers with 15 or more client ratings were considered. This criterion was similar to the one used in the research by Maselli and Fabo (2015). This can significantly reduce the sample, but it also guarantees that all the cases finally chosen are workers with a minimum degree of experience and involvement with the DLM, which is relevant to our research objective. Thus, we avoid cases of workers who have only had occasional experiences on these platforms.

TaskRabbit's activity is mainly located in the United States (hereinafter US). Therefore, we decided to download data from the main American cities in terms of population because TaskRabbit's development has been associated with the size of the cities where the platform operates (Isaac, 2015). After exploring the three main cities (New York, Chicago, and Los Angeles), we found that in the next five, Houston, Philadelphia, Phoenix, San Antonio, and San Diego, only seven, one, two, zero, and seven workers with more than 15 reviews were available, respectively. Thus, we did not explore cities with smaller populations, with the exception of two cases. First, we decided to consider Boston because it is where the TaskRabbit offices are located, which could mean that the population would be more familiar with the platform. Because we found enough workers (42) in this city who fulfilled the aforementioned requirement, they were included. Second, we also decided to explore the case of San Francisco because it was one of the first cities where TaskRabbit started to operate after Boston. In fact, the number of workers who met the selection criterion was also quite large in this city (43).

A total of 290 workers with 15 or more client ratings were selected. For each of them, the data shown in Table 2 were downloaded. Regarding these data, TaskRabbit does not show the number of times workers have carried out each of the different types of tasks. Alternatively, it shows the number of client reviews received for each type of task. This figure can be used as a proxy for the number of times the different types of tasks have been performed.

In the case of Trip4real, all the destinations where this platform operated were explored. In all, 175 workers with 15 or more client ratings from 16 destinations were included, although $80 \%$ of them belonged to seven cities, as shown in the next section. On the Trip4real platform, the

${ }^{2}$ http://www.abc.es/economia/abci-airbnb-compra-startup-espanola-trip4real-201609191334_noticia.html 
Table 2. Characteristics of the platforms and workers' information downloaded from them

\begin{tabular}{|c|c|c|}
\hline PLATFORM & TaskRabbit & Trip4real \\
\hline WORK & Large variety of tasks, mostly physical tasks & Tourist experience activities \\
\hline WORKERS & 290 & 175 \\
\hline $\begin{array}{l}\text { WORKERS' } \\
\text { DATA }\end{array}$ & $\begin{array}{l}\text { Year of incorporation into the platform } \\
\text { Total number of tasks performed } \\
\text { Total number of reviews } \\
\text { Number of reviews received on each of the different types of } \\
\text { tasks (proxy for the number of times the different types of } \\
\text { tasks have been performed) }\end{array}$ & $\begin{array}{l}\text { Year of incorporation into the platform } \\
\text { Total number of activities offered } \\
\text { Total number of reviews } \\
\text { Number of activities offered in each type } \\
\text { of activities that the platform } \\
\text { intermediated } \\
\text { Length of each activity }\end{array}$ \\
\hline
\end{tabular}

number of reviews is not a suitable proxy for the number of times each activity was carried out because most of these activities are performed for groups of clients, and thus one activity could produce more than one review. Table 2 shows the downloaded worker data.

\section{Analysis}

Descriptive statistics were calculated to describe the workers' activity. Following Ketchen and Shook's (1996) suggested procedures, a hierarchical cluster analysis using Ward's hierarchical method was used to evaluate the existence of different kinds of workers. A multivariate analysis of variance (MANOVA) was applied to determine the overall significance of the differences among the groups.

\section{Results}

\section{Sample data}

Table 3 collects the total number of workers found with 15 or more reviews and their territorial distribution. In both platforms, there is a high concentration of workers in one city: New York in the case of TaskRabbit and Barcelona in the case of Trip4real. In addition, in both platforms, most of the workers joined the platform in 2014 and 2015 (79.6\% in the case of TaskRabbit and $75.4 \%$ in the case of Trip4real).

\section{Workload}

Table 4 shows the number of tasks workers have performed since their incorporation as taskers in TaskRabbit. The following are the descriptive statistics for the tasks performed by the workers: $m=240.16, \mathrm{SD}=252.40$, maximum $=1,767$, median $=151$, percentile $75=314.25$. Statistics are based on all the tasks. That is, the tasks of workers who joined TaskRabbit in 2013, for example, include the total figures (years 2013, 2014, and 2015). Percentile 75 indicates that, regardless of the year the workers joined the platform, a quarter of the workers performed a large number of tasks.

In order to find out the number of hours involved in the previous number of tasks, the De Groen, Maselli, and Fabo (2016) finding that the most common task length in a platform similar to TaskRabbit was between 2 and $3 \mathrm{hr}$ can be used. Thus, assuming a 2-hr task length, on average, workers would have worked a total of $480.32 \mathrm{hr}$. In order to figure out workers' work hours annually, we will only consider workers who joined the platform in 2015 (for workers who joined the platform in 2013, for example, it is unknown how many tasks correspond to 2013, 2014, or 2015). In 2015, workers would have worked an average of $295.26 \mathrm{hr}$, whereas the worker who was at percentile 75 would have worked $372 \mathrm{hr}$, and the one who performed the most tasks would have worked $1,240 \mathrm{hr}$. 
Table 3. Workers on the platforms by city

\begin{tabular}{|c|c|c|c|}
\hline \multicolumn{2}{|l|}{ TaskRabbit } & \multicolumn{2}{|c|}{ Trip4real } \\
\hline Cities & Workers (\%) & Cities & Workers (\%) \\
\hline New York & 34.8 & Barcelona & 25.1 \\
\hline Los Angeles & 16.9 & Lisbon & 12.0 \\
\hline San Francisco & 14.8 & Paris & 10.9 \\
\hline Boston & 14.5 & London & 11.4 \\
\hline Chicago & 13.1 & Rome & 7.4 \\
\hline Houston & 2.4 & Madrid & 7.4 \\
\hline San Diego & 2.4 & Amsterdam & 5.7 \\
\hline Phoenix & 0.7 & Edinburgh & 4.6 \\
\hline \multirow[t]{8}{*}{ Philadelphia } & 0.3 & Seville & 3.4 \\
\hline & & Girona & 3.4 \\
\hline & & Berlin & 2.3 \\
\hline & & Dublin & 1.7 \\
\hline & & Zaragoza & 1.1 \\
\hline & & Cordoba & 1.1 \\
\hline & & Granada & 1.1 \\
\hline & & Mallorca & 1.1 \\
\hline Total & 100.0 & Total & 100.0 \\
\hline$N$ & 290 & $N$ & 175 \\
\hline
\end{tabular}

In the case of Trip4real, the platform did not publish the number of activities that individuals had performed. Trip4real published the different activities each worker offered. The following are the descriptive statistics for the activities offered by workers who had 15 or more reviews: $m=3.35, \mathrm{SD}=3.04$, maximum $=18$, median $=2$, and percentile $75=5$ (Table 5 ). Thus, although the tasks performed through TaskRabbit are not directly comparable with the activities offered through Trip4real, it seems clear that the Trip4real numbers are much lower.

\section{Client reviews}

In TaskRabbit, the selected workers had an average of 147.40 client reviews $(S D=154.45)$. Thus, the ratio of reviews to tasks actually delivered is 0.61 ; that is, $61 \%$ of the tasks are reviewed by customers. In Trip4real, the selected workers have an average of 106.26 client reviews $(\mathrm{SD}=226.62)$.

\section{Type of work in TaskRabbit}

As explained above, in TaskRabbit, the number of client reviews received for each type of task may be used as a proxy for the number of times each type of task was performed. In fact, the correlation between tasks and reviews is $0.977(p=.00)$, and the review and task statistics are relatively close (.61). We found that individuals performed 44 different types of tasks. These tasks 
Table 4. Task statistics of earning workers in TaskRabbit according to the year they joined the platform

\begin{tabular}{|c|c|c|c|c|c|c|c|}
\hline Year & Workers & Mean of tasks & SD & Median & Maximum & Minimum & P. 75 \\
\hline 2009 & 1 & $1,767.00$ & - & - & 1,767 & 1,767 & - \\
\hline 2010 & 1 & $1,430.00$ & - & - & 1,430 & 1,430 & - \\
\hline 2011 & 2 & 894.00 & 478.00 & 894.00 & 1,232 & 556 & - \\
\hline 2012 & 7 & 397.14 & 364.50 & 159.00 & 954 & 52 & 694.00 \\
\hline 2013 & 48 & 414.18 & 310.04 & 351.00 & 1,628 & 29 & 549.50 \\
\hline 2014 & 74 & 253.85 & 212.86 & 205.50 & 1,029 & 33 & 316.50 \\
\hline 2015 & 157 & 147.63 & 112.08 & 113.00 & 620 & 25 & 186.00 \\
\hline Total & 290 & 240.16 & 252.40 & 151.00 & 1,767 & 25 & 314.25 \\
\hline
\end{tabular}

Note: P. $75=$ Percentile 75 .

are portrayed in Table 6, along with the percentage of workers who performed each task and the percentage of each type of task out of the 69,647 total tasks.

Table 6 shows that more than half of the workers performed one or several of the following four types of tasks: delivery, furniture assembly, moving help, and lift and shift furniture. By contrast, very few workers (less than $3 \%$ ) performed the following tasks: automotive, web design and development, senior and disabled care, accounting, sewing, videography, window cleaning, and entertainment. Although TaskRabbit offers workers the opportunity to perform a great variety of tasks, the reality is that eight types of tasks represented $82.3 \%$ of all the rated work. They are the following: delivery (14.8\%), furniture assembly (14.2\%), moving help (14.2\%), lift and shift furniture (10.7\%), minor home repairs (11.7\%), cleaning (9.6\%), mounting (4.9\%), and yardwork and removal (2.4\%). Furthermore, on average, workers performed 7.1 types of different tasks $(\mathrm{SD}=3.5)$.

Although the previous data reflect homogeneous activity on the platform, the existence of different groups of workers was explored through a hierarchical cluster analysis based on the

Table 5. Activities in Trip4real, workers who offer them, and descriptive statistics

\begin{tabular}{|c|c|c|c|c|c|c|}
\hline Activities & $\begin{array}{l}\% \text { of workers who offer } \\
\text { the activities* }\end{array}$ & $\begin{array}{c}\text { Mean of activities offered per } \\
\text { worker in the category }\end{array}$ & SD & $\begin{array}{c}\% \text { of } \\
\text { activities }\end{array}$ & Length ${ }^{\star \star}$ & SD \\
\hline Routes & 72.0 & 2.92 & 2.05 & 62.6 & 3.29 & 2.63 \\
\hline Gastronomy & 29.1 & 2.37 & 2.14 & 20.6 & 3.11 & 1.86 \\
\hline $\begin{array}{l}\text { Sports and } \\
\text { adventure }\end{array}$ & 11.4 & 2.45 & 3.83 & 8.3 & 5.54 & 4.59 \\
\hline $\begin{array}{c}\text { Day trips and } \\
\text { excursions }\end{array}$ & 9.1 & 1.81 & 1.38 & 4.9 & 6.37 & 2.61 \\
\hline Workshops & 4.0 & 1.00 & 0.00 & 1.2 & 3.36 & 2.15 \\
\hline Nightlife & 4.0 & 1.00 & 0.00 & 1.2 & 3.30 & 1.32 \\
\hline $\begin{array}{c}\text { Nature and } \\
\text { unwind }\end{array}$ & 2.9 & 1.40 & 0.89 & 1.2 & 3.83 & 2.03 \\
\hline Total & & 3.35 & 3.04 & 100.0 & 3.60 & 2.61 \\
\hline
\end{tabular}

Note: $n=175$.

${ }^{\star}$ The total is more than $100 \%$ because each worker can offer activities in more than one category.

${ }^{\star \star}$ Mean of hours. 
Table 6. Tasks in TaskRabbit, percentage of workers who perform each of them, and frequency of the tasks

\begin{tabular}{|c|c|c|c|c|c|}
\hline Type of tasks & $\%$ of workers & $\%$ of tasks & Type of tasks & $\%$ of workers & $\%$ of tasks \\
\hline Delivery & 70.3 & 14.8 & Decoration & 12.8 & 0.2 \\
\hline Furniture assembly & 65.5 & 14.2 & Computer help & 12.1 & 0.6 \\
\hline Moving help & 62.1 & 14.2 & Data entry & 11.4 & $0.5 \%$ \\
\hline Lift and shift furniture & 55.5 & 10.7 & Event planning & 10.3 & 0.3 \\
\hline Executive assistant & 39.0 & 2.1 & Carpentry, construction & 9.7 & 0.5 \\
\hline Cleaning & 37.6 & 9.6 & Electrician & 9.3 & 0.6 \\
\hline Minor home repairs & 37.2 & 11.7 & Writing and editing & 7.6 & 0.2 \\
\hline Shopping & 35.9 & 1.5 & Cooking & 6.2 & 0.1 \\
\hline Event staffing & 35.9 & 1.5 & Plumbing & 4.8 & 0.3 \\
\hline Errands & 32.8 & 0.8 & Photography & 4.5 & 0.1 \\
\hline Mounting & 31.4 & 4.9 & Arts & 4.5 & $0.0^{*}$ \\
\hline Organization & 29.7 & 1.8 & Marketing & 3.1 & 0.1 \\
\hline Yardwork and removal & 28.0 & 2.4 & Selling on line & 3.1 & $0.0^{*}$ \\
\hline Packing and shipping & 25.9 & 0.8 & Graphic design & 2.8 & 0.1 \\
\hline Wait in line & 22.4 & 0.8 & Automotive & 2.8 & $0.0^{*}$ \\
\hline Painting & 22.1 & 1.4 & Sewing & 1.4 & 0.1 \\
\hline Research & 18.3 & 1.1 & Web design, development & 1.4 & 0.1 \\
\hline Usability testing & 17.2 & 0.5 & Accounting & 1.4 & $0.0^{*}$ \\
\hline Pet sitting & 15.5 & 0.3 & Senior and disabled care & 1.4 & $0.0^{*}$ \\
\hline Office administration & 15.2 & 0.5 & Window cleaning & 1.0 & $0.0^{\star}$ \\
\hline Deep cleaning & 14.8 & 0.6 & Videography & 1.0 & $0.0^{*}$ \\
\hline Laundry and ironing & 12.8 & 0.2 & Entertainment & 1.0 & $0.0^{\star}$ \\
\hline
\end{tabular}

Note: ${ }^{*}$ These tasks are being performed, but their percentage is below $0.05 \%$

number of tasks of each type performed by each worker. Previously, a principal components analysis of the 44 tasks using Varimax rotation was conducted to reduce the number of variables for classification. This analysis produced 16 factors that explained $72.4 \%$ of the task variance. Because the task 'event planning' had a communality of 0.374 , it was removed, and the principal component analysis was performed again. The Kaiser-Meyer-Olkin index was 0.607, and Bartlett's test of sphericity was significant at $p=.00$. A three-cluster solution was identified by the cluster analysis.

These groups were clearly different in terms of size. There was one main group composed of 279 individuals whose activity was not focused on a particular task. This group was characterized by doing numerous physical tasks, such as, minor home repairs, yardwork and removal, moving help, lifting furniture, acting as staff in events, handyman tasks, furniture assembly, cleaning, and cooking. Therefore, it was labeled manual labor workers.

The other two groups were less relevant in terms of representativeness of the sample. One consisted of six individuals who performed a relatively high number of tasks related to 
videography, graphic design, design and development, online selling, and computer help. Thus, it was labeled computer-based workers.

The third group was made up of five individuals who were relatively high on tasks involving research, marketing, usability testing, waiting in line, entertainment, and office administration. The label of marketing and procedure helpers was proposed.

The robustness of the cluster classification was tested using MANOVA to determine that the overall clusters differed from one another. MANOVA confirmed the differences among the three clusters $(p=.000$; Pillai's Trace, $F=72.677$; Wilks' Lambda, $F=72.516$; Hotelling's Trace, $F=72.354$; Roy's Largest Root, $F=78.203$ ).

\section{Type of work in Trip4real}

In the case of Trip4real, Table 5 shows that most of the activity the platform produces consists of tourist routes $(72.0 \%$ of workers and $62.6 \%$ of the activities).

The existence of different groups of workers was also explored through a hierarchical cluster analysis. A four-cluster solution was identified. Two groups had similar sizes. The first group consisted of 76 individuals who stood out for both their routes and day trips and excursion activities, and so they were called guides. The second group consisted of 79 individuals who offered, in each category, fewer activities than the average, and so they were considered a low variety group.

The third group was composed of 19 individuals who clearly stood out for their gastronomy offer (e.g., 'Barcelona Promenade and Authentic Tapas in Gothic Quarter,' 'Mad Hatter's Tea Party: East London Dining Experience'), and so they were called gastronomes. Finally, the last cluster was made up of one individual who focused his activity only on sports and adventure, with a significant repertory of 18 activities.

The robustness of the cluster classification was tested using MANOVA to determine that the overall clusters differed from one another. MANOVA confirmed the differences among the four clusters ( $p=.000$; Pillai's Trace, $F=47.866$; Wilks' Lambda, $F=54.698$; Hotelling's Trace, $F=59.401$; Roy's Largest Root, $F=111.160$ ).

Finally, Table 5 also shows that Trip4real's workers offered activities that on average involved a length of $3.6 \mathrm{hr}(\mathrm{SD}=2.61)$. Day trips and excursion activities were the activities that took the most time $(6.37 \mathrm{hr})$, followed by sports and adventure $(5.54 \mathrm{hr})$.

\section{Earnings}

In order to determine worker earnings in both platforms, data about the number of tasks performed and their respective rates are needed. As explained above, in TaskRabbit, it is possible to know the approximate number of tasks workers have performed in each task category through the number of reviews. Because, like other labor digital platforms, TaskRabbit publishes the initial worker fees for each of the work categories, it is possible to get an idea of a worker's gross income. It must be taken into consideration that TaskRabbit deducts $30 \%$ of the worker income ( $15 \%$ if the client has previously required the individual's services). The worker who had done the most tasks in our sample $(1,767)$ could have had an average annual gross income of $\$ 37,754.18$. The worker who was at the median in our sample would have reached an average annual gross income of $\$ 15,077.98$. In order to find nonaveraged annual earnings, only workers who joined the platform in 2015 were considered. In this year, the individual who performed the highest number of tasks (620) would have earned $\$ 63,006.50$. Likewise, the workers at percentile 75 (186 tasks) and at the median (113 tasks) on the number of tasks would have made $\$ 23,436$ and $\$ 8,189.87$, respectively.

In the case of Trip4real, the previous way of estimating workers' earnings may produce figures that are far from real because we did not have a suitable proxy for the number of times the different activities were performed. 


\section{Discussion}

DLM work seems to share many of the characteristics usually attributed to nonstandard work arrangements. Therefore, it is not a completely different kind of work but rather, as Katz and Krueger (2016) state, an additional form of nonstandard employment. At the same time, it is true that the DLM introduces some changes in the way that people work. Thus, digital platforms allow anyone to easily connect with consumers without the necessity of making any investment. Similarly, workers can now offer different types of skills within the same marketplace, since one digital platform can host many different kinds of consumer demands. Further, the presence of visible and easily accessible consumer ratings is also a novelty that did not exist before. DLM thus introduces some developments that are not present in the offline labor market.

Regarding the work content, the tasks performed by our sample coincide with the tasks that workers perform in other forms of nonstandard working arrangements. Nevertheless, as the TaskRabbit cluster analysis highlights, the novelty is that most individuals do not perform interrelated bundles of tasks. This is not usual in other nonstandard employment. That is, workers who work for companies on temporary or part time contracts, as well as those hired through temporary work agencies (e.g., cooks, gardeners, and cleaners) are usually employed for specific occupations that include interrelated tasks. In the DLM, on the other hand, workers perform bundles of tasks that are not related, such as minor repairs, yardwork, event staffing, cleaning and cooking. Therefore, in order to earn income in the digital on-demand economy individuals must be willing to perform several different types of tasks.

On the other hand, some of the unfavorable characteristics of the DLM found in the literature were confirmed. Nevertheless, some nuances should be considered. DLM work is not always low skilled. This type of work exists, but there is also work that demands sophisticated skills. Thus, the segmentation of skill levels that DLM theory proposes was found. For example, the work found in a platform such as TaskRabbit basically requires a low level of skills because more than $80 \%$ of the tasks performed on this platform consist of basic blue-collar work. Although TaskRabbit also intermediates in work that seems to require more sophisticated skills, these tasks represent less than $3 \%$ of all the tasks performed. These results are consistent with the main group of workers found on the platform: a large group of workers who basically perform various physical and low-skilled tasks.

However, Trip4real clearly intermediated more high skilled work. Tourist routes represent the activity most frequently offered to clients (62.6\%), and most of the workers (72.0\%) provided it. Thus, cluster analysis revealed one main group made up of guides. Because these routes were carried out in cities, this activity often requires specialized knowledge about history and art that must be demonstrated to clients (Huang, Hsu, \& Chan, 2010). Furthermore, routes involved an intense interaction with clients for an average of $3.3 \mathrm{hr}$. All the activities in Trip4real involved service encounters where interpersonal relationship skills had to be displayed.

The workers' workload is not comparable to that of a permanent and full time job. Working through the platforms analyzed seems to be a part-time occupation. This is more evident in the case of TaskRabbit, where the estimated number of hours worked is far from those of a permanent and full time occupation. The reasons for this (i.e., voluntary decision or low demand) are unknown. Nevertheless, the number of tasks that workers performed through TaskRabbit $(m=240.16$, median $=151)$ was significantly higher than the data found in the study by De Groen, Maselli, and Fabo (2016). These findings coincide with Hall and Krueger (2015), who showed that most of the Uber drivers drove less than $35 \mathrm{hr} /$ week. In addition, a consequence of the previous figures is that, unlike what has sometimes been proposed, working long days is not the most common situation for the workers considered.

Another characteristic of the work performed in the DLM in this study is the short length of the demanded tasks. TaskRabbit does not provide data about this, although it is not too risky to guess that the tasks included in Table 6 do not involve long-term relationships. Trip4real showed 
the length of the activities that workers offered. Figures in Table 5 confirm the short duration of the work performed through Trip4real $(m=3.35, \mathrm{SD}=3.04)$.

Calculations of workers' income yield earnings higher than those found in the literature. The studies by De Groen, Maselli, and Fabo (2016) reveal a maximum income of $€ 5,663$ in 2 years. According to our estimations with the data obtained from TaskRabbit, the highest income workers have earned much more. Even those individuals located at the median had higher earnings ( $\$ 8,189.87$ in 2015). The study by Maselli and Fabo (2015) shows earnings even lower than those found by De Groen, Maselli, and Fabo (2016). Both studies are based on smaller platforms than TaskRabbit. Our results support the hypothesis by De Groen, Maselli, and Fabo (2016) about the influence of platform size on workers' income.

The scarce literature seems to show that making a living based only on digital labor platforms is quite difficult. Our results support this belief, based on percentile data. In 2015, the worker at percentile 75 shows earnings that seem insufficient to make a living. Thus, three-quarters of the workers will probably have earned less than $\$ 23,436$. It must be kept in mind that, from these calculated incomes, the platform deducts $30 \%$ (15\% if the client has previously required services from the same individual). The same thing occurs when the earnings are calculated for workers who joined the platform before 2015. Therefore, most individuals' earnings are probably far below employees' average annual income of \$49,630 in the US (Bureau of Labor Statistics, 2017). In addition, as self-employed workers, taskers at TaskRabbit must deal with the costs of health services and unemployment situations. Therefore, these data join Hall and Krueger's (2015) findings that $61 \%$ of Uber drivers performed another job while working through the platform. Nevertheless, three comments must be highlighted. First, workers' real income might be lower than what can be deduced from the published rates because individuals can reduce their rates when negotiating the service with clients. Second, as Maselli and Fabo (2015) state, workers' real income might be higher because once clients meet the workers, they can agree on new services without the platform's intermediation. Third, as we will discuss in the next paragraph, workers have low earnings not because the tasks are poorly paid, but because the number of tasks they do, on average, is relatively low.

In order to determine whether DLM work is fairly paid, minimum wage data can be used as a reference (Maselli \& Fabo, 2015). Based on the assumed average task length of $2 \mathrm{hr}$, the individual who has performed the most tasks overall would have a gross hourly income of $\$ 74.78$. This figure significantly exceeds the $\$ 10$ minimum wage of the state where this individual works. The same thing occurs in the case of the worker who performed the highest number of tasks in $2015(\$ 59.78 / \mathrm{hr})$ and the one who was at the median $(\$ 36.24 / \mathrm{hr})$ : in all cases, the earnings per hour were higher than the minimum wage in their states. If instead of the minimum wages in each of the states, the average hourly wages of the most common tasks performed using TaskRabbit are considered (between $\$ 20$ and $\$ 30$ according to the Bureau of Labor Statistics, 2017), in all of the previous cases the income per hour would be higher than the average hourly wages. Unlike Maselli and Fabo's (2015) study, our results indicate that, at TaskRabbit, a fulltime worker could make a living if the average annual income of $\$ 49,630$ in the US is used as the criterion, even taking into consideration the time dedicated to activities such as changing clothes, tool maintenance, commuting, negotiation with clients, and budgeting, which these workers must do, but for which they do not receive any direct compensation.

Another characteristic mentioned in the literature is the strong competition workers have to face. The results show that, in both platforms, the most frequent tasks are performed by a large number of workers. These workers clearly compete with each other through their fees, reviews, client interactions, and images of the activities in the case of Trip4real. Similarly, the number of workers varies in the different cities or tourist destinations where the platforms operate. Therefore, in cities such as New York and Barcelona, the competition will be higher than in places such as Philadelphia and Amsterdam, respectively. 
The last characteristic that these workers' data allow us to assess is the subordination to the customer's experience. Both platforms attach a large number of client reviews to the workers' profiles. Our results confirm the client's habit of reviewing workers' services because the ratio between the tasks reviewed and the number of tasks was 0.61 in TaskRabbit. Getting a bad rating can seriously affect the worker's reputation because individuals have been found to be more influenced by negative information than positive (Rozin \& Royzman, 2001).

In summary, this research shows that, at least from a theoretical point of view, the DLM potentially allows workers to make a living, since the hourly income for this type of work exceeds both state-mandated minimum wages and average earnings for different types of tasks. However, the reality is much more complex.

In fact, our results confirm that most tasks in digital marketplaces are of very short length which means that workers would need to do at least three to four tasks per day in order to earn a decent wage. However, securing multiple tasks per day is not easy to do for several reasons. On the one hand, there is the superstar effect discussed above (Codagnone, Abadie, \& Biagi, 2016). On the other hand, we have found that offerings consistently exceed the demand for services: we were only able to find 290 workers that had performed more than 15 tasks out of more than 30,000 workers that were available in the platform when we collected our sample. Additionally, there is a very high subordination to user experience, which leverages the effect of the offer exceeding the demand even further. Lastly, as people discover and are more willing to use these types of services, it can appear that the demand is growing. However, the offerings can grow even more quickly, as anyone can begin offering services immediately, especially in areas that do not require specialized skills.

Thus, all of this can lead us to be very skeptical about the potential of the DLM to provide a viable means of making a living to a large group of individuals. Anyone working in this type of market would need to adopt one or several of the following working strategies: (1) providing services across several platforms in order to receive orders from different areas (e.g., renting a property, driving, mounting furniture, etc.); (2) finding a part-time offline job that will complement the income from DLM tasks; or (2) creating innovative strategies to stand out significantly from other providers and thus to get more assignments. Although all of these strategies are possible, each has inherent complexities that make them difficult to implement. For example, renting a property though Airbnb, driving for Uber, and offering services through TaskRabbit, can be quite challenging, as time frames can collide and different kinds of problems may arise in each job.

Therefore, at a first glance it seems that the DLM is currently well-suited for complementary income. However, our findings show that the DLM is not something that can be used by the majority of workers to make a living.

\section{Conclusion}

DLM work coincides with the characteristics of existing nonstandard work arrangements. However, it has a much higher potential for reaching a very high volume, because it is based on digital platforms. The market has grown significantly in the last few years, and is expected to grow further in coming years. In general, statements about work in DLM rely on platform's rules and/or on few cases of workers. Therefore, figures obtained through qualitative research approaches are not enough, and thus there has been a demand for independent studies based on bigger samples of workers (Schor, 2017). This research provides empirical evidence to many of the statements that are frequently made about what working in the digital on-demand economy involves. This type of work consists basically of short-term labor that may require low or high skills. In any case, clients' experiences are quite important because the habit of rating workers' performance is very common. According to our data, the option of the DLM as a way of making a living would require performing a number of tasks far beyond the median number of tasks 
found in this research. Thus, as a full-time occupation, it is currently possible, but only for a very small group of individuals, which contributes to the insufficiently tested superstar effect that can exist in the DLM (Codagnone, Abadie, \& Biagi, 2016). Therefore, institutions and platforms should consider the option of promoting actions to support gig workers. Although more research is needed, in theory, these actions would address issues such as workers' health care protection, training, activity costs, retirement, and unemployment coverage. However, it must be stated that, when the income per hour is considered, the earnings are much higher than each state's minimum wage, and they are also higher than the average hourly wages for tasks such as those considered in this study.

\section{Limitations and directions for further research}

Data from two digital labor platforms have been analyzed. Although the results provide quantitative information in a field that needs it, due to the resistance of platforms to provide their data (Schor, 2017), the generalization of the findings is not possible. Additionally, as mentioned above, TaskRabbit's results for the number of different types of tasks performed were inferred from the number of client reviews published in each work category. Furthermore, income figures are based on an average task length of $2 \mathrm{hr}$. This is a conservative figure, and individual real income could be higher. In addition, individuals' opinions and attitudes about DLM have not been considered. They could reveal that a percentage of the individuals do not desire full-time dedication, or that they want to combine their work on the platforms with another job. In these cases, many of the criticisms mentioned in the literature would not be completely justified, and so it is necessary to obtain workers' personal opinions and more data, in order to advance the knowledge about this new form of work. Finally, in this study we did not have information about the personal characteristics of the workers analyzed (i.e., age, gender, work experience, education, previous income, etc.), which would have been useful for putting our results in context.

Acknowledgements. None

\section{References}

Aloisi, A. (2016). Commoditized workers. Case study research on labour law issues arising from a set of 'on-demand/gig economy' platforms. Comparative Labor Law \& Policy Journal 37(3), 653-684.

Atkinson, J. (1984). Manpower strategies for flexible organizations. Personnel Management 16(8), $28-31$.

Berg, J. (2016). Income security in the on-demand economy: Findings and policy lessons from a survey of crowdworkers, International Labour Organization. Geneva. Retrieved February 18, 2017, from http://www.ilo.org/wcmsp5/groups/ public/—ed_protect/—protrav/—travail/documents/publication/wcms_479693.pdf

Bureau of Labor Statistics (2017). May 2016 National Occupational Employment and Wage Estimates. USA. Retrieved May 10, 2018, from http://www.bls.gov/oes/current/oes_nat.htm

Cochrane, R., \& McKeown, T. (2015). Vulnerability and agency work: From the workers' perspectives. International Journal of Manpower 36(6), 947-965.

Codagnone, C., Abadie, F., \& Biagi, F. (2016). The Future of Work in the 'Sharing Economy'. Market Efficiency and Equi Opportunities or Unfair Precarisation? (JRC Science for Policy Report EUR 27913 EN). Institute for Prospective Technological Studies. Retrieved June 22, 2016, from https://papers.ssrn.com/sol3/papers.cfm?abstract_id=2784774

Davis, GF. (2015). What might replace the modern corporation: Uberization and the web page enterprise. Seattle University Law Review 39, 501-515.

De Groen, WP., Maselli, I., \& Fabo, B. (2016). The Digital Market for Local Services: A one night stand for workers? (CEPS Special Report No. 133). Retrieved July 18, 2016, from https://papers.ssrn.com/sol3/papers.cfm?abstract_id=2766220

De Stefano, VD. (2016). The Rise of the 'just-in-time workforce': On-demand work, crowdwork and labour protection in the 'gig-economy'. International Labour Office Conditions of Work and Employment Series. Geneve. Retrieved January 12, 2017, from https://ecampus.itcilo.org/pluginfile.php/25267/mod_page/content/35/Conditions\%20of\%20Work\%20and \%20Employment\%20Series\%20No.\%2071.pdf

Doeringer, PP., \& Piore, MJM. (1971). Internal labor markets and manpower analysis. New York: D.C. Heath and Company. Drahokoupil, J., \& Fabo, B. (2016). The platform economy and the disruption of the employment relationship. ETUI Policy Brief, 5, 1-6. Retrieved May 14, 2018, from https://www.etui.org/Publications2/Policy-Briefs 
Elance-Odesk. (2014). The many faces of work fulfillment. Retrieved January 12, 2016, from https://blog-static.odesk.com/ content/Elance-oDeskAnnualImpactReport2014.pdf

European Commission (2016). A European agenda for the collaborative economy. Retrieved September 20, 2016, from http://ec.europa.eu/DocsRoom/documents/16881

Gheorghe, M. (2015). State of freelancing in IT and future trends. World Academy of Science, Engineering and Technology. International Journal of Social, Behavioral, Educational, Economic, Business and Industrial Engineering, 9(5), $1434-1438$.

Goldin, C., \& Katz, L. (2009). The race between education and technology. Cambridge, MA: Harvard University Press.

Graham, M., Hjorth, I., \& Lehdonvirta, V. (2017). Digital labour and development: Impacts of global digital labour platforms and the gig economy on worker livelihoods. Transfer: European Review of Labour and Research, 23(2), 135-162.

Hall, JV., \& Krueger, AB. (2015). An analysis of the labor market for Uber's driver-partners in the United States. Retrieved January 16, 2016, from https://assets.documentcloud.org/documents/1507970/uberstudy.pdf

Horemans, J. (2016). Polarisation of non-standard employment in Europe: Exploring a missing piece of the inequality puzzle. Social Indicators Research, 125(1), 171-189.

Huang, S., Hsu, CH., \& Chan, A. (2010). Tour guide performance and tourist satisfaction: A study of the package tours in Shanghai. Journal of Hospitality \& Tourism Research, 34(1), 3-33.

Hudson, K. (2007). The new labor market segmentation: Labor market dualism in the new economy. Social Science Research, $36(1), 286-312$.

Huws, U. (2015). iCapitalism and the cybertariat: Contradictions of the digital economy. Monthly Review, 66(8), 42-57.

Huws, U. (2016). Platform labour: Sharing economy or virtual wild west. Journal for a Progressive Economy, 1, $24-27$.

Huws, U., Spencer, NH., \& Syrdal, DS. (2018). Online, on call: The spread of digitally organised just-in-time working and its implications for standard employment models. New Technology, Work and Employment, 33(2), 113-129.

Isaac, E. (2015). Innovative clusters and new work: A case study of TaskRabbit, Berkeley Roundtable on the International Economy (BBRIE Working Paper 2015-2). Retrieved January 12, 2016, from http://www.brie.berkeley.edu/wp-content/ uploads/2015/02/Innovative-Clusters-New-Work.pdf

Jepsen, AL. (2007). Factors affecting consumer use of the Internet for information search. Journal of Interactive Marketing, 21 (3), 21-34.

Kalleberg, AL. (2003). Flexible firms and labor market segmentation: Effects of workplace restructuring on jobs and workers. Work and Occupations, 30(2), 154-175.

Kalleberg, AL., \& Dunn, M. (2016). Good jobs, bad jobs in the gig economy. Perspectives on Work, 20, 10-14. Retrieved May 24, 2018, from http://lerachapters.org/OJS/ojs-2.4.4-1/index.php/PFL/article/viewFile/3112/3087

Katz, LF., \& Krueger, AB. (2016). The rise and nature of alternative work arrangements in the United States, 1995-2015. (National Bureau of Economic Research, No. w22667). Retrieved January 12, 2017, from http://www.nber.org/papers/ w22667

Ketchen, DJ. Jr., \& Shook, CL. (1996). The application of cluster analysis in strategic management research: An analysis and critique. Strategic Management Journal, 17(6), 441-458.

Kiang, MY., Raghu, TS., \& Shang, KHM. (2000). Marketing on the internet-who can benefit from an online marketing approach? Decision Support Systems, 27(4), 383-393.

Leighton, P. (2016). Professional self-employment, new power and the sharing economy: Some cautionary tales from Uber. Journal of Management \& Organization, 22(6), 859-874.

Lehdonvirta, V. (2017). The online gig economy grew 26\% over the past year. Retrieved July 20, 2017, from http://ilabour.oii. ox.ac.uk/the-online-gig-economy-grew-26-over-the-past-year/

Maselli, I., \& Fabo, B. (2015). Digital workers by design? An example from the on-demand economy (CEPS Working Document No. 414/October 2015). Retrieved January 12, 2016, from http://aei.pitt.edu/68757/

Noguera Vivo, JM., Martínez Sánchez, J., Nicolás Ojeda, MÁ., Pérez Escolar, M., Grandío Pérez, MDM., Hernández Gómez, F., \& Sánchez Cobarro, PDH. (2014). Economía de la Participación. Madrid: Fundación EOI.

Organisation for Economic Co-operation and Development (2016). Working party on measurement and analysis of the digital economy. New forms of work in the digital economy. OECD. Retrieved July 20, 2017, from http://www.oecd.org/ officialdocuments/publicdisplaydocumentpdf/?cote=DSTI/ICCP/IIS(2015)13/FINAL\&docLanguage=En

Rozin, P., \& Royzman, EB. (2001). Negativity bias, negativity dominance, and contagion. Personality and Social Psychology Review, 5(4), 296-320.

Scholz, T. (Ed.) (2013). Digital labor: The internet as playground and factory. New York: Routledge.

Schor, JB. (2017). Does the sharing economy increase inequality within the eighty percent?: Findings from a qualitative study of platform providers. Cambridge Journal of Regions, Economy and Society, 10(2), 263-279.

Schor, JB., \& Attwood-Charles, W. (2017). The 'sharing' economy: labor, inequality, and social connection on for-profit platforms. Sociology Compass, 11(8), 1-16.

Shontell, A. (2011). My nightmare experience as a TaskRabbit Drone. Retrieved January 12, 2016, from http://www. businessinsider.com/confessions-of-a-task-rabbit-2011-12

Slaughter, AM. (2015). The gig economy can actually be great for women. Wired. Retrieved January 26, 2016, from http:// www.wired.com/2015/10/unfinished-business-women-men-work-family 
Sprague, R. (2015). Worker (Mis) classification in the sharing economy: Square pegs trying to fit in round holes. Retrieved January 26, 2016, from http://works.bepress.com/cgi/viewcontent.cgi?article=1054\&context=robert_sprague

Spreitzer, GM., Cameron, L., \& Garrett, L. (2017). Alternative work arrangements: Two images of the new world of work. Annual Review of Organizational Psychology and Organizational Behavior, 4, 473-499.

Sundararajan, A. (2014). Peer-to-peer businesses and the sharing (collaborative) economy: Overview, economic effects and regulatory issues. Written testimony for the hearing titled The Power of Connection: Peer to Peer Businesses. Retrieved January 26, 2016, from http://smbiz.house.gov/uploadedfiles/1-15-2014_revised_sundararajan_testimony.pdf

Sundararajan, A. (2016). The sharing economy: The end of employment and the rise of crowd-based capitalism. Cambridge, MA: MIT Press.

Todolí-Signes, A. (2017). The end of the subordinate worker? The on-demand economy, the gig economy, and the need for protection for crowdworkers. International Journal of Comparative Labour Law and Industrial Relations, 33(2), 241-268.

United States Department for Labor (2016). The future of work: Diving into the data. Retrieved July 28, 2017, from https:// blog.dol.gov/2016/06/17/the-future-of-work-diving-into-the-data

Cite this article: Melián-González S, Bulchand-Gidumal J. (2018). What type of labor lies behind the on-demand economy? New research based on workers' data. Journal of Management \& Organization X: 1-17, doi: 10.1017/jmo.2018.53 